\title{
MACHADO CONTISTA EM ANTOLOGIAS EM LÍNGUA INGLESA
}

\author{
Luana Ferreira de Freitas* \\ Universidade Federal do Ceará \\ Cynthia Beatrice Costa** \\ Universidade Federal de Santa Catarina
}

\begin{abstract}
Resumo: O presente artigo objetiva fazer uma análise da contística machadiana traduzida para a língua inglesa. Esta análise busca entender se a produção dos contos traduzidos privilegia e explora a tese do "milagre" em que a grandeza de Machado é explicada como uma excrescência em um Brasil pobre e atrasado ou se buscam mostrar um Machado mais próximo da sua própria realidade pessoal, consciente de lacunas estruturais e cioso na construção cuidadosa e paulatina da sua literatura madura.
\end{abstract} Palavras-chave: Machado de Assis. Contos traduzidos. Milagre.

*Doutorado em Teoria Literária na Universidade Federal de Santa Catarina (UFSC), em 2007, e pós-doutorado no Programa de Pós-Graduação em Estudos da Tradução, da mesma universidade. É uma das fundadoras e primeira coordenadora da POET - Pós-Graduação em Estudos da Tradução da Universidade Federal do Ceará (UFC). Atualmente, além de professora na área de letras da UFC, atua como vice-coordenadora do GT de Tradução da ANPOLL, gestão 2014-2016. Pesquisa, entre outros temas, literatura inglesa, tradução literária e estilo e obras machadianas traduzidas para o inglês. Fortaleza, Ceará, Brasil. E-mail: luanafreitas.luana@gmail.com

** Formação em Comunicação Social e mestrado em Crítica Literária, PUC-SP. Atualmente, faz doutorado no Programa de Pós-Graduação em Estudos da Tradução da Universidade Federal de Santa Catarina (UFSC), sobre traduções em inglês do romance Dom Casmurro. Florianópolis, Santa Catarina, Brasil. E-mail: cynthia@editorapoetisa.com 


\title{
MACHADO DE ASSIS' STORIES IN ANTHOLOGIES IN ENGLISH
}

\begin{abstract}
This article aims to analyze Machado's short stories translated into English. This analysis seeks to examine if these translated short stories explore and emphasize the thesis of the "miracle" according to which Machado's greatness is explained as a fortuitous event in a poor and backward Brazil or if they reflect a Machado closer to his own personal reality, conscious of structural gaps in the careful and gradual construction of his mature literature.
\end{abstract}

Keywords: Machado de Assis. Translated short stories. Miracle.

Contrariamente a vários estudiosos da obra machadiana, brasileiros e estrangeiros, não acreditamos na tese de Machado ser um milagre inexplicável, quase uma aberração em meio a um atraso tropical, mulato e pobre. Milagres, em geral, podem ser explicados ou revelados com alguma dedicação e tempo empregado.

Ao se defender a tese do milagre estético machadiano no Brasil do século XIX, duas questões saltam aos olhos: a primeira é que se Machado fosse mesmo um milagre, ele teria nascido já pronto, inteiro, definitivo. Seu primeiro romance teria sido Memórias póstumas de Brás Cubas em vez de Ressurreição, e, quanto à ficção curta, sua carreira teria se iniciado com contos como "Dona Paula", "Um homem célebre" ou "Noite de almirante", para citar três da madura contística machadiana. Esse primeiro aspecto pontuado negaria a Machado, em última análise, o seu percurso e suas leituras, ou seja, o pecúlio que foi acumulando e do qual se serviu ao longo de sua carreira. Afrânio Coutinho, a esse respeito, afirma:

Certo vezo brasileiro de encarar o artista como um produto espontâneo e precoce não dá lugar para se compreender que a arte é a resultante de longa paciência, de esforço continuado de pesquisa, estudo, reflexão. Machado de Assis é um exemplo disso. Sua maneira não surgiu abruptamente, desde o início, na juventude virgem. Foi o produto da ex- 
periência acumulada, do estudo e trato dos grandes modelos, da obediência às regras e às disciplinas do ofício. Seu progresso foi constante e ascensional. (ASSIS, 2004, p. 26)

O próprio Machado, ao falar sobre emancipação intelectual, defende a autonomia mediante pesquisa e reflexões ininterruptas, sem pressa: "É mais fácil regenerar uma nação que uma literatura. Para esta não há gritos de Ipiranga; as modificações operam-se vagarosamente; e não se chega a um só momento a um resultado" (2004, p. 787)

A segunda questão a que nos referimos parece um tanto mais complexa e tem implicações talvez mais graves. Há, subjacente à aparentemente inexplicável genialidade de Machado, ao caráter maravilhoso atribuído aos seus escritos, uma lógica condescendente com a qual a crítica brasileira, quase sempre parte de uma elite branca, e a estrangeira conseguem lidar sem lhes deslegitimar. Afinal, como explicar que um pobre mulato brasileiro, que nunca estudou na Europa, pudesse ser um grande escritor? Como explicar a universalidade de Machado se ele nunca deixou o Rio de Janeiro? Como aceitar o reconhecimento de Machado como maior escritor brasileiro por grande parte da crítica em meio a tantas adversidades? Assim, o recurso ao milagre torna a grandeza mestiça palatável. O outro lado da mesma moeda seria a subtração de uma vida intelectual sofisticada no Brasil de então, impondo a visão de um país exclusivamente rural ignorando a existência de um sistema cultural complexo, que produziu figuras como José de Alencar, Carlos Gomes e Joaquim Nabuco.

Longe de ser um elogio, o rótulo de "milagre" busca empalidecer não apenas Machado e sua legítima grandeza, como também as letras brasileiras e, em última instância, a vida intelectual no país.

A carreira de contista de Machado inicia-se em 1858, aos 19 anos, com a publicação de "Três tesouros perdidos" n' $A$ Marmo$t a^{l}$. Ao longo dos 50 anos de carreira de contista, Machado escreveu 218 contos, de acordo com Djalma Cavalcante e Luis Filipe Ribeiro. Nossa intenção é ver se as antologias publicadas em lín- 
gua inglesa em que figuram a contística de Machado privilegiam e exploram o tal "milagre" ou se buscam, com o recente interesse estrangeiro pelo Brasil, mostrar um Machado mais próximo da própria realidade, consciente de lacunas estruturais e cioso na construção cuidadosa e paulatina da sua literatura madura.

Os contos de Machado tiveram sua primeira aparição em inglês ${ }^{2}$ provavelmente em 1917, quando o estadunidense Isaac Goldberg, estudioso de literaturas em línguas de origem latina, publicou uma tradução de "O enfermeiro" na revista Stratford Journal, com o título de "The Attendant's Confession”. Em 1919, ele publicaria outro conto, "Viver!", traduzido como "Life", no mesmo periódico. Essas duas traduções, mais a de "A cartomante" (como "The Fortune-Teller") foram reunidas na primeira antologia mista de contos em língua inglesa, Brazilian Tales, publicada em Boston e organizada pelo próprio Goldberg.

Após a republicação da tradução de Goldberg de "O enfermeiro" em uma antologia de 1936, novos contos de Machado só voltariam a ser traduzidos em 1963, 42 anos mais tarde, em antologia intitulada The Psychiatrist and Other Stories, que, organizada por William Grossman, contou também com traduções de Helen Caldwell. Naquele mesmo ano, Caldwell publicou o conto avulso "What Went On With the Baroness': a tale with a point", tradução de "Um apólogo", em formato de livro-folheto, por uma editora independente da Califórnia.

Seriam necessários, depois, mais 14 anos para que fosse publicada mais uma coletânea com contos inéditos. Em 1977 surge The Devil's Church and Other Stories, organizada e traduzida por Jack Schmitt e Lorie Ishimatsu, que, se por um lado, são em geral criticados pela tradução, por outro ofereceram aos anglófonos uma seleção de 19 contos traduzidos. Essa antologia retomou apenas um conto já publicado por Goldberg em 1921, "O enfermeiro", traduzindo-o agora como "The Companion". Os outros contos publicados eram inéditos à época.

Midnight Mass, tradução de William Grossman de "Missa do Galo", apareceu no mesmo ano em dois volumes: na coletânea 
editada por ele e Caldwell, e em Short Stories of the Masters (algo como "Contos dos Mestres"). Quase 40 anos antes, em 1925, um conto machadiano já havia aparecido em publicação semelhante, uma antologia de melhores contos do mundo, "from literatures of all periods and countries", isto é, de literaturas de todos os períodos e países. Nessa mesma linha, em 1972, uma edição especial da revista Reader's Digest, intitulada Great Short Stories of the World republicou a tradução de William Grossman de "Noite de Almirante" (“Admiral's Night). Em 1973, "Midnight Mass" reaparece em Contemporary Latin American Short Stories, outra antologia do tipo "os melhores contos" organizada por Pat McNees com o estranho nome de "contemporânea" - já que boa parte dos contos ali presentes, incluindo o de Machado, não eram contemporâneos à época da publicação. De toda forma, essa tendência editorial, de Machado de Assis figurar entre os grandes contistas da América Latina e, às vezes, do mundo, será mais fortemente notada nos anos 2000, como será mostrado adiante.

Ainda nos anos 1970, o tradutor Neil Miller publicou quatro contos avulsos em revistas especializadas, todas nos Estados Unidos. Em 1972, a revista Américas, publicada em Washington DC, publicou o seu "The Nurse", a segunda tradução conhecida de "O enfermeiro", depois da de Goldberg e anterior à de Schmitt e Ishimatsu. No ano seguinte, em 1973, apareceu na Américas, novamente, e na Latin American Review o conto "A igreja do diabo" traduzido por Miller como “The Devil's Church" e ilustrado por Samuel Muschkin - portanto, a tradução de Miller desse conto é a primeira conhecida, também anterior à da dupla Schmitt e Ishimatsu. Cinco anos depois, em 1978, foi a vez de Miller publicar "Wedding Song" (tradução de "Cantiga de Esponsais") na Américas e "A Fable", sua versão de "Um Apólogo", já traduzido por Caldwell, no periódico Pacific Moana Quarterly. Duas das traduções de Miller foram publicadas em livro três décadas depois, na antologia da Oxford organizada por K. D. Jackson.

Os anos 1980 e 1990 foram marcados por contos machadianos publicados em inglês de maneira avulsa, em periódicos, websites 
ou antologias genéricas. Em 1986, Alfred Mac Adam assinou a tradução de "Curta História", publicado como "A Short Story", na revista Literature and Arts of the Americas. Quase uma década depois, em 1995, Wilson Loria registrou os direitos de sua tradução de "O Espelho", como "The Mirror", que mais tarde apareceria no website Brazzil, ainda hoje no ar.

No que diz respeito a livros, houve aparições pontuais de Machado em coletâneas no fim do século XX. Duas vezes em coletâneas de narrativas latino-americanas, e uma, A Hammock Beneath the Mangoes (algo como Uma Rede Sob as Mangueiras), é dedicada a contos do mundo tropical e/ou exótico, como indica o nome. Thomas Colchie selecionou o mesmo conto, "The Psychiatrist" traduzido por William Grossman, nas duas compilações que organizou, em 1992 e 1993.

Além da retomada do trabalho de Grossman, nota-se, ainda, uma espécie de "boom" de "O Alienista", que, embora tenha ganhado uma nova tradução apenas em 1998 por Alfred Mac Adam, apareceu em três livros em um curto espaço de sete anos. A edição de luxo "The Alienist", de 1998, ilustrada por Carroll Dunham, é considerada uma raridade preciosa e hoje circula apenas pelas mãos de colecionadores. Já "Missa do Galo", outra tradução de Grossman retomada nos anos 1990, foi o único conto machadiano selecionado por Roberto Echevarría para aparecer em The Oxford Book of Latin American Short Story.

O cenário mudará no século XXI. Com o passar dos anos, as traduções de contos machadianos se multiplicam, denunciando um crescente interesse editorial - ainda que no âmbito, sobretudo, universitário - concentrado nos Estados Unidos, como se observa na tabela: 


\begin{tabular}{|c|c|c|c|c|}
\hline CONTO & $\begin{array}{c}\text { BRAZILIAN } \\
\text { TALES* } \\
1921 \\
\text { Org. e trad. de Isaac } \\
\text { Goldberg } \\
3 \text { contos } \\
\text { inéditos }\end{array}$ & $\begin{array}{c}\text { THE PSYCHIATRIST AND } \\
\text { OTHER STORIES } \\
1963 \\
\text { Org. William Grossman e } \\
\text { Helen Caldwell } \\
12 \text { contos } \\
\text { inéditos }\end{array}$ & $\begin{array}{c}\text { DEVIL'S CHURCH AND } \\
\text { OTHER STORIES } \\
1977 \\
\text { Org. e trad. Jack Schmitt } \\
\text { e Lorie Ishimatsu } \\
18 \text { contos } \\
17 \text { inéditos }\end{array}$ & $\begin{array}{c}\text { OXFORD ANTHOLOGY } \\
\text { OF THE BRAZILIAN SHORT } \\
\text { STORY } \\
2006 \\
\text { Org. K. David Jackson } \\
10 \text { contos } \\
3 \text { inéditos }\end{array}$ \\
\hline $\begin{array}{c}\text { Contos Fluminenses (1870) } \\
7 \text { contos: } 2\end{array}$ & $\emptyset$ & $\emptyset$ & $\emptyset$ & $\emptyset$ \\
\hline $\begin{array}{l}\text { Histórias da meia-noite } \\
\text { (1873) } \\
6 \text { contos: } 2\end{array}$ & $\emptyset$ & $\emptyset$ & $\emptyset$ & $\emptyset$ \\
\hline $\begin{array}{l}\text { Papéis avulsos (1882) } \\
\qquad 12 \text { contos: } 9\end{array}$ & $\emptyset$ & $\begin{array}{c}0 \text { Alienista; } \\
\text { Teoria do medalhão; } \\
0 \text { espelho; } \\
\text { Verba testamentária }\end{array}$ & $\emptyset$ & $\emptyset$ \\
\hline $\begin{array}{l}\text { Histórias sem data (1884) } \\
18 \text { contos: } 16\end{array}$ & $\emptyset$ & Noite de almirante; & $\begin{array}{l}\text { A igreja do diabo; } \\
\text { Singular ocorrência; } \\
\text { Conto alexandrino; } \\
\text { Primas de Sapucaia; } \\
\text { A segunda vida }\end{array}$ & $\begin{array}{l}\text { Cantiga de esponsais; } \\
\text { Academias de Sião }\end{array}$ \\
\hline $\begin{array}{c}\text { Várias histórias (1896) } \\
16 \text { contos: } 16\end{array}$ & $\begin{array}{l}\text { A cartomante; } \\
0 \text { enfermeiro; } \\
\text { Viver! }\end{array}$ & $\begin{array}{l}\text { Uns braços; } \\
\text { A causa secreta }\end{array}$ & $\begin{array}{l}\text { Um homem célebre; } \\
\text { Adão e Eva; } \\
\text { O enfermeiro; } \\
\text { O diplomático; } \\
\text { Mariana; } \\
\text { Dona Paula }\end{array}$ & $\begin{array}{l}\text { A cartomante; } \\
\text { Uns braços; } \\
\text { A causa secreta; } \\
\text { O enfermeiro; } \\
\text { Dona Paula; } \\
\text { Viver! }\end{array}$ \\
\hline $\begin{array}{l}\text { Páginas recolhidas (1899) } \\
\qquad 8 \text { contos: } 8\end{array}$ & $\emptyset$ & $\begin{array}{l}0 \text { caso da vara; } \\
\text { Missa do galo }\end{array}$ & $\begin{array}{c}\text { Eterno!; } \\
\text { Ideias de canário }\end{array}$ & $\emptyset$ \\
\hline $\begin{array}{l}\text { Relíquias de casa velha } \\
\qquad \begin{array}{l}\text { (1906) } \\
9 \text { contos: } 9\end{array}\end{array}$ & $\emptyset$ & $\begin{array}{l}\text { Pai contra mãe; } \\
\text { Umas férias }\end{array}$ & $\begin{array}{l}\text { Marcha fúnebre; } \\
\text { Suje-se, gordo!; } \\
\text { Evolução; } \\
\text { Pílades e Orestes }\end{array}$ & $\begin{array}{l}\text { Pai contra mãe; } \\
\text { Suje-se, gordo! }\end{array}$ \\
\hline Contos avulsos & $\emptyset$ & Jogo do bicho & Mariana & $\emptyset$ \\
\hline
\end{tabular}




\begin{tabular}{|c|c|c|c|c|}
\hline CONTO & $\begin{array}{c}\text { A CHAPTER OF HATS AND } \\
\text { OTHER STORIES } \\
2008 \\
\text { Org. e trad. de John } \\
\text { Gledson } \\
20 \text { contos } \\
4 \text { inéditos }\end{array}$ & $\begin{array}{l}\text { A MACHADO DE ASSIS } \\
\text { ANTHOLOGY } \\
2011 \\
\text { Org. Rosalia Garcia e } \\
\text { lan Alexander } \\
17 \text { contos } \\
6 \text { inéditos }\end{array}$ & $\begin{array}{c}\text { THE ALIENIST AND OTHER } \\
\text { STORIES OF } 19^{\text {th }} \text { CENTURY } \\
\text { BRAZIL } \\
2013 \\
\text { Org. e trad. Chasteen } \\
8 \text { contos } \\
1 \text { inédito }\end{array}$ & $\begin{array}{l}\text { TALES OF OLD BRAZIL } \\
2013 \\
\text { Francis K. Johnson } \\
5 \text { contos } \\
4 \text { inéditos }\end{array}$ \\
\hline $\begin{array}{c}\text { Contos Fluminenses (1870) } \\
7 \text { contos: } 2\end{array}$ & $\emptyset$ & $\emptyset$ & $\emptyset$ & Frei Simão \\
\hline $\begin{array}{l}\text { Histórias da meia-noite } \\
\text { (1873) } \\
6 \text { contos: } 2\end{array}$ & $\emptyset$ & $\emptyset$ & $\emptyset$ & $\emptyset$ \\
\hline $\begin{array}{l}\text { Papéis avulsos (1882) } \\
\qquad 12 \text { contos: } 9\end{array}$ & $\begin{array}{l}\text { Na arca; } \\
0 \text { espelho }\end{array}$ & $\begin{array}{c}\text { A chinela turca; } \\
\text { Na arca; } \\
\text { A sereníssima república }\end{array}$ & $\begin{array}{l}0 \text { Alienista; } \\
\text { Teoria do medalhão; } \\
0 \text { espelho }\end{array}$ & $\emptyset$ \\
\hline $\begin{array}{l}\text { Histórias sem data (1884) } \\
18 \text { contos: } 16\end{array}$ & $\begin{array}{l}\text { Singular ocorrência; } \\
\text { Capítulo dos chapéus; } \\
\text { Conto alexandrino; } \\
\text { Primas de Sapucaia; } \\
\text { Noite de almirante }\end{array}$ & $\begin{array}{l}\text { A igreja do diabo; } \\
\text { Noite de almirante }\end{array}$ & $\begin{array}{l}\text { Singular ocorrência; } \\
\text { Capítulo dos chapéus }\end{array}$ & $\emptyset$ \\
\hline $\begin{array}{c}\text { Várias histórias (1896) } \\
16 \text { contos: } 16\end{array}$ & $\begin{array}{c}\text { A cartomante; } \\
\text { Uns braços; } \\
\text { Um homem célebre; } \\
\text { A desejada das gentes; } \\
\text { A causa secreta; } \\
\text { 0 diplomático; } \\
\text { Conto de escola; } \\
\text { Dona Paula }\end{array}$ & $\begin{array}{l}\text { A cartomante; } \\
\text { Uns braços; } \\
\text { Um homem célebre; } \\
\text { A causa secreta; } \\
\text { O enfermeiro; } \\
\text { Conto de escola; } \\
\text { Um apólogo }\end{array}$ & $\emptyset$ & 0 enfermeiro \\
\hline $\begin{array}{l}\text { Páginas recolhidas (1899) } \\
\qquad 8 \text { contos: } 8\end{array}$ & $\begin{array}{l}0 \text { caso da vara; } \\
\text { Missa do galo }\end{array}$ & $\begin{array}{l}0 \text { caso da vara; } \\
0 \text { dicionário; } \\
\text { Missa do galo }\end{array}$ & $\emptyset$ & $\emptyset$ \\
\hline $\begin{array}{l}\text { Relíquias de casa velha } \\
\qquad \begin{array}{c}\text { (1906) } \\
9 \text { contos: } 9\end{array}\end{array}$ & $\begin{array}{l}\text { Pai contra mãe; } \\
\text { Evolução; } \\
\text { Pílades e Orestes }\end{array}$ & $\emptyset$ & Pai contra mãe & $\emptyset$ \\
\hline Contos avulsos & $\emptyset$ & $\begin{array}{l}\text { Um esqueleto; } \\
\text { Terpsícore }\end{array}$ & $\begin{array}{l}\text { Vinte anos! Vinte anos!; } \\
\text { Terpsícore }\end{array}$ & $\begin{array}{l}\text { Capitão Mendonça; } \\
0 \text { caso Barreto; } \\
\text { A vida eterna }\end{array}$ \\
\hline
\end{tabular}




\begin{tabular}{|c|c|c|c|}
\hline CONTO & $\begin{array}{c}\text { EX-CATHEDRA } \\
2014 \\
\text { Org. Glenn Alan Cheney, } \\
\text { Luciana Tanure, Rachel } \\
\text { Kopit } \\
21 \text { contos } \\
19 \text { inéditos }\end{array}$ & $\begin{array}{c}\text { MIDNIGHT MASS AND } \\
\text { OTHER STORIES } \\
2014 \\
\text { Org. Juan LePuen } \\
19 \text { contos: } \\
10 \text { inéditos }\end{array}$ & $\begin{array}{c}\text { JOAQUIM MARIA MACHADO } \\
\text { DE ASSIS } \\
\text { STORIES } \\
2014 \\
\text { Org. e trad. Rhett MCNeil } \\
14 \text { contos } \\
2 \text { inéditos }\end{array}$ \\
\hline $\begin{array}{c}\text { Contos Fluminenses (1870) } \\
7 \text { contos: } 2\end{array}$ & $\emptyset$ & Miss Dollar & $\emptyset$ \\
\hline $\begin{array}{l}\text { Histórias da meia-noite } \\
\text { (1873) } \\
6 \text { contos: } 2\end{array}$ & $\emptyset$ & $\begin{array}{l}\text { O relógio de ouro; } \\
\text { Ponto de vista }\end{array}$ & $\emptyset$ \\
\hline $\begin{array}{l}\text { Papéis avulsos (1882) } \\
\qquad 12 \text { contos: } 9\end{array}$ & $\begin{array}{c}0 \text { empréstimo; } \\
\text { Uma visita de Alcebíades }\end{array}$ & $\emptyset$ & $\begin{array}{c}\text { OAlienista; } \\
\text { Na arca; } \\
\text { Uma visita de Alcebíades }\end{array}$ \\
\hline $\begin{array}{l}\text { Histórias sem data (1884) } \\
18 \text { contos: } 16\end{array}$ & $\begin{array}{l}\text { Cantiga de esponsais; } \\
\text { Uma senhora; } \\
\text { Anedota pecuniária; } \\
\text { Fulano; } \\
\text { A segunda vida; } \\
\text { Manuscrito de um } \\
\text { sacristão; } \\
\text { Ex-cathedra; } \\
\text { A senhora do Galvão; } \\
\text { Academias de Sião }\end{array}$ & Cantiga de esponsais & $\begin{array}{l}\text { Cantiga de esponsais; } \\
\text { Uma senhora; } \\
\text { Ex-cathedra; } \\
\text { Academias de Sião }\end{array}$ \\
\hline $\begin{array}{c}\text { Várias histórias (1896) } \\
16 \text { contos: } 16\end{array}$ & $\begin{array}{c}\text { Entre santos; } \\
\text { Trio em lá menor; } \\
\text { Viver!; } \\
\text { Cônego ou a metafísica } \\
\text { do estilo }\end{array}$ & $\begin{array}{l}\text { Uns braços; } \\
\text { A causa secreta; } \\
\text { Trio em lá menor; } \\
0 \text { diplomático; } \\
\text { Conto de escola }\end{array}$ & $\begin{array}{c}\text { Trio em lá menor; } \\
0 \text { diplomático; } \\
\text { Viver!; } \\
\text { Cônego ou a metafísica } \\
\text { do estilo }\end{array}$ \\
\hline $\begin{array}{l}\text { Páginas recolhidas (1899) } \\
\qquad 8 \text { contos: } 8\end{array}$ & $\begin{array}{c}0 \text { erradio; } \\
\text { Lágrimas de Xerxes; } \\
\text { Papéis velhos }\end{array}$ & Missa do galo & 0 dicionário \\
\hline $\begin{array}{l}\text { Relíquias de casa velha } \\
\qquad \begin{array}{c}\text { (1906) } \\
9 \text { contos: } 9\end{array}\end{array}$ & $\begin{array}{c}\text { Maria Cora; } \\
\text { Um capitão de voluntários; } \\
\text { Anedota do cabriolet }\end{array}$ & Umas férias & $\emptyset$ \\
\hline Contos avulsos & $\emptyset$ & $\begin{array}{l}\text { Capitão Mendonça; } \\
0 \text { machete; } \\
\text { A mulher pálida; } \\
\text { Trina e uma; } \\
\text { Uma partida; } \\
\text { Flor anônima; } \\
\text { Um incêndio; } \\
\text { 0 escrivão Coimbra }\end{array}$ & $\begin{array}{c}0 \text { imortal; } \\
\text { Viagem à roda de mim } \\
\text { mesmo }\end{array}$ \\
\hline
\end{tabular}


Observa-se, com base na tabela, que, no início dos anos 2000, três antologias retomaram contos machadianos já traduzidos e publicados anteriormente. A edição compilada por Kenneth David Jackson, Oxford Anthology of the Brazilian Short Story, em que constam dez contos de Machado, republica traduções de Isaac Goldberg, Helen Caldwell, Jack Schmitt e Lorie Ishimatsu e publica pela primeira vez em livro traduções de Neil Miller que antes haviam aparecido apenas em revistas especializadas, nos anos 1970.

Na primeira década dos anos 2000, Machado de Assis aparece, portanto, em três antologias de "literatura mundial" e em duas coletâneas especificamente "brasileiras", na editada por Jackson para a Oxford e em um volume que combina turismo e literatura organizado por Alexis Levitin para uma editora independente de livros de viagem, que publica pela primeira e única vez o conto "A Carteira", traduzido como "The Wallet". Nesse contexto, parece haver uma tendência (ainda que do ponto de vista acadêmico e/ou independente) de retirar Machado de Assis do âmbito unicamente latino-americano, localizando-o ou em seu país, ou colocando-o em pé de igualdade com grandes nomes da literatura ocidental, como ocorre no volume organizado por James Daley - o nome de Machado aparece na capa junto com o de Maupassant, Tolstoi, Mann, Woolf, Hemingway, Borges, entre outros canônicos.

Em 2008, 45 anos após a empreitada de Grossman e Caldwell e mais de três décadas depois da seleção de contos inéditos de Schmitt e Ishimatsu, é a vez de John Gledson organizar a terceira grande coletânea machadiana em língua inglesa, com 20 contos dos quais, porém, apenas quatro são traduções inéditas: "Na Arca" (traduzido como "In the Ark: Three Unpublished Chapters of Genesis"); "Capítulo dos Chapéus" ("A Chapter of Hats"; "Conto de Escola” (“A Schoolboy’s Story”); e "A Desejada das Gentes” (The Cynosure of All Eyes"). Os outros 16 contos já haviam sido traduzidos e publicados nas duas grandes coletâneas anteriores, denunciando, talvez, certa timidez na escolha para essa nova seleção. Em 2012, na edição inaugural da revista Machado de Assis Magazine, especializada em traduções de obras brasileiras para outros idio- 
mas, aparece novamente o conto "The Cane", tradução de Gledson de "O Caso da Vara" que faz parte da antologia.

O mesmo ocorrerá no início dos anos 2010, quando um grupo de graduandos e pós-graduandos, sob a supervisão da professora Rosalia Garcia, do Instituto de Letras da Universidade Federal do Rio Grande do Sul, publicou A Machado de Assis Anthology com 17 contos, dos quais seis eram então inéditos em inglês. Que haja grupos de estudo ou de pesquisa em universidades brasileiras se ocupando da tradução da nossa literatura, ou, até mesmo, monografias em que textos literários sejam traduzidos não tem nada de extraordinário. Contudo, a antologia organizada por Garcia destaca-se por figurar entre os títulos à venda na Amazon, de onde adquirimos uma cópia digital.

Paralelamente às publicações de livros, surgem duas novidades: a tradução até então inédita do conto "O Imortal”, realizada por Alfred Mac Adam e publicada em The Hudson Review, em 2009, como "The Immortal" (mais tarde, em 2014, outra tradução do mesmo conto aparecerá na coletânea de Rhett McNeil); e "The Old Senate", única tradução até o momento de "O Velho Senado", assinada por Anthony Doyle na revista brasileira Estudos Avançados.

As repetições de contos já traduzidos em outras décadas, no entanto, serão dribladas por quatro grandes antologias recentes, como se vê na tabela. Nota-se a profusão de coletâneas nesses últimos anos. Em 2013, John Charles Chasteen organizou, prefaciou e traduziu The Alienist and Other Stories of Nineteenth-Century Brazil. Chasteen, que é professor de história latino-americana do século XIX da universidade da Carolina do Norte e tradutor do português e do espanhol de ficção e não-ficção, selecionou oito contos, porém apenas um inédito, "Vinte Anos! Vinte Anos!", como "To Be Twenty Years Old!".

No mesmo ano de 2013, a Norton Anthology of World Literature republicou a tradução de Helen Caldwell de "O Caso da Vara”. Francis K. Johnson, ainda em 2013, lançou em seu pouco divulgado Tales From Old Brazil quatro contos inéditos em inglês: "Mr. Barreto" (tradução de "O Caso Barreto"); "Life Eternal" 
(“A Vida Eterna"); "Brother Simão" ("Frei Simão"); e "Captain Mendonça" ("Capitão Mendonça”).

Foi em 2014, entretanto, que os contos de Machado passaram por um renascimento em língua inglesa, com o lançamento de três coletâneas de grande porte. Glenn Alan Cheney e outros colaboradores reuniram 21 contos, traduzidos por 21 tradutores diferentes, em Ex-Cathedra. Juan LePuen em Midnight Mass and Other Stories também selecionou 21 contos para a sua compilação, dos quais 12 inéditos. Já Rhett McNeil listou 14 contos em seu Joaquim Maria Machado de Assis Stories, que traz o nome do autor brasileiro em grande destaque na capa - mas apenas um deles é uma tradução inédita, "Voyage Around Myself" ("Viagem à Roda de Mim Mesmo"), já que Alfred Mac Adam publicou a sua tradução de "O Imortal" (também traduzido como "The Immortal") na The Hudson Review em 2009.

Além dos contos que podemos considerar "obrigatórios" por constarem em várias publicações, tais como $O$ Enfermeiro, $O$ Alienista e $A$ Cartomante, é curioso ver, com base na cronologia das edições, como há contos que parecem estar "na moda" em determinados períodos. As três coletâneas de 2014, por exemplo, trazem versões de "Trio em Lá Menor", nunca antes publicado. O mesmo ocorre com "Cantiga de Esponsais", que já havia aparecido na coletânea da Oxford organizada por Kenneth David Jackson, com tradução de Neil Miller. "O Diplomático" aparece nas coletâneas de Juan LePuen e de RhettMcNeil,

Ao longo dos noventa e oito anos em que a contística machadiana aparece para o público de língua inglesa, temos, além dos contos avulsos, publicados em websites e periódicos, 22 antologias, 14 mistas e nove exclusivas de Machado. Das 14 antologias mistas, quatro são compostas exclusivamente por contos brasileiros, três por contos latino-americanos, uma com pretensões exóticas, indicando postura colonialista com as culturas de partida, e seis consistem em antologias de literatura mundial, das quais quatro foram publicadas no século XXI. Das nove antologias exclusivas de Machado, seis foram lançadas nos últimos seis anos, o que indica 
uma visibilidade crescente do autor em língua inglesa.

Ainda assim, cabe observar, as empreitadas para a projeção de Machado em língua inglesa, mesmo as mais recentes, são levadas a cabo, na maioria das vezes, por professores universitários, o que indica a pouca ou nenhuma inserção do autor no mercado comercial, ou seja, Machado não vende para o grande público, indicando, em última instância, que o autor não conseguiu ultrapassar os muros da academia no mundo anglófono.

Isaac Goldberg, o primeiro tradutor de Machado em inglês, lecionou literatura hispânica em Harvard e se dedicou a um cuidadoso estudo das literaturas de línguas espanhola e portuguesa nas Américas. Helen Caldwell, considerada "brasilianista", era professora da Universidade da Califórnia, embora não lecionasse literatura, mas sim línguas clássicas. Entre os outros nomes de destaque, William L. Grossman foi professor da Universidade de Nova York; Jack Schmitt, da Universidade Estadual da Califórnia; Lori Ishimatsu, da Universidade de Indiana; John Gledson (único britânico do grupo), da Universidade de Liverpool. K. David Jackson e Robert González Echeverría são, ambos de Yale e John Charles Chasteen, da Universidade da Carolina do Norte. Nesse contexto, uma exceção interessante é Thomas Colchie, importante agente literário de Nova York que selecionou Machado para duas de suas coletâneas nos anos 1990.

Por outro lado, o interesse acadêmico tem se mostrado bastante forte nos últimos anos, uma indicação de que, embora a inserção mercadológica não tenha se consolidado, existe ao menos uma intenção de fazer com que isso aconteça. Um novo horizonte parece estar se abrindo: Juan LePuen apresenta-se como escritor, tradutor e editor, assim como Glenn Alan Cheney, que, embora já tenha lecionado cursos livres em universidades e estudado Letras na Universidade Federal de Minas Gerais, trabalha atualmente como escritor, jornalista e tradutor. Rhett McNeil, por sua vez, é doutorando e professor na Universidade Estadual do Arizona e assim mantém a tradição acadêmica de publicações machadianas. 
Chama a atenção, sobretudo, a seleção de contos de duas antologias: A Chapter of Hats and Other Stories, de John Gledson, e $A$ Machado de Assis Anthology, de Rosalia Garcia. Ora, se considerarmos que a organização de antologia prevê a seleção de textos, tradução e produção de paratexto, é de se estranhar que justamente duas antologias recentes ofereçam tão poucas novidades para o público anglófono: em 37 contos, apenas nove contos inéditos.

Cabe destacar essas antologias pelos seus organizadores: John Gledson, crítico e tradutor de Machado, reconhecido no Brasil e no estrangeiro como estudioso e conhecedor da obra de Machado, e Rosalia Garcia, professora universitária, tradutora e pesquisadora em estudos literários da tradução no Brasil. Chamou a nossa atenção a pouca ousadia desses organizadores/tradutores na seleção de contos, uma vez que, pela própria natureza da empreitada, podiam ter exposto outro Machado ao público de língua inglesa.

Por outro lado, em 2012 Juan LePuen trouxe 12 traduções inéditas em sua compilação, enquanto Ex-Cathedra, a antologia de 2014 organizada por Glenn Alan Cheney e outros colaboradores, trouxe o número representativo de 16 contos nunca antes publicados em inglês. Originários de Papéis Avulsos (Uma Visita de Alcibíades, O Empréstimo), Relíquias da Casa Velha (Um Capitão de Voluntários, Anedota do Cabriolet, Maria Cora), Várias Histórias (Entre Santos, O Cônego ou Metafísica do Estilo), Páginas Recolhidas (Um Erradio, Lágrimas de Xerxes, Papéis Velhos) e Histórias Sem Data (Ex-Cathedra, Manuscrito de um Sacristão, A Senhora do Galvão, Uma Senhora, Fulano, Anedota Pecuniária), os contos de Ex-Cathedra podem indicar a intenção de abrangência por parte dos organizadores.

Tem-se em língua inglesa, entre 1917 e 2015, ou seja, ao longo 98 anos, 82 traduções de contos de Machado. Os contos mais traduzidos nas antologias foram "O enfermeiro", "Uns braços", "A causa secreta", "A missa do galo", "O Alienista”, "Viver!", "O diplomático", "Cantiga de esponsais", "A cartomante", "Pai contra mãe", "O espelho", "Noite de almirante", "Singular ocorrência", "Um homem célebre", "As academias de Sião", "Na arca", 
"Conto de escola" e "Trio em lá maior". Cabe observar ainda que todos os contos das coletâneas Várias Histórias (1896), Páginas Recolhidas e (1899) e Relíquias da Casa Velha (1906) foram traduzidos, indicando que a seleção de contos, em sua maioria, privilegiou a produção madura de Machado, ou o que se convencionou chamar de segunda fase, para ser mais exata, no caso dos contos, a partir de 1882, com a publicação de Papéis avulsos.

Paulo Henriques Britto, em recente conferência na UFSC, no I Colóquio de Literatura Traduzida: Antologias, coletâneas e coleções, falou a respeito de critérios para a seleção de textos para uma antologia: se representativo da obra geral ou se representativo em termos de qualidade. No caso em análise, o critério foi claramente o segundo, o que, em última instância, corrobora a tese do milagre com a qual iniciamos o artigo.

Se fossem mais frequentes a ousadia e a abrangência em coletâneas de língua inglesa, talvez o público anglófono pudesse saber (parodiando Bentinho) se o Machado dos primeiros contos já estava dentro do de Papéis Avulsos, ou se este foi mudado naquele por efeito de algum caso incidente.

\section{Notas}

1 Revista de variedades do Rio de Janeiro.

${ }^{4}$ Agradecemos a K. David Jackson, que nos ajudou a localizar alguns dos contos traduzidos para o inglês em revistas e livros pouco divulgados. 


\section{Referências}

ASSIS, Machado de. The Alienist. Trad. Alfred Mac Adam. Ilust. Carroll Dunham. San Francisco: Arion Press, 1998.

. The Alienist. Trad. William L. Grossman. New York: Melville House, 2012.

. "The Attendant's Confession". Trad. Isaac Goldbeg. In: Stratford Journal 1, pp. 6-16, 1917.

$\overline{1,2012}$.

. "The Cane”. Trad. John Gledson. In: Machado de Assis Magazine, v.

. "The Devil's Church". Trad. Neil Miller. Ilust. Samuel Muschkin. In: Américas, v. 8-9, 1973.

. "The Devil's Church". Trad. Neil Miller. In: Latin American Library Review, v. 1, n. 2, 1973.

. “A Fable”. Trad. Neil Miller. In: Pacific Moana Quarterly, v. 3-4, 1978.

. "The Immortal". Trad. Alfred Mac Adam. In: The Hudson Review, v. 61, n. 4. 2009.

. "Life”. Trad. Isaac Goldberg. In: Stratford Journal 5.3, pp. 119-129, 1919. 67, 2009.

. "The Old Senate". Trad. Anthony Doyle. In: Estudos Avançados 23, n. . "A Short Story". Trad. Alfred Mac Adam. In: Literature and Arts of the Americas, v. 19, n. 36, 1986.

BROWN, Marshall. The Longman Anthology of World Literature - Volume E, the nineteenth century. New York: Pearson-Longman, 2004. 
CLARK, Barrett Harper; LIEBER, Maxim (Org.). Great Short Stories of the World: a collection of complete short stories chosen from literatures of all periods and countries. Cleveland: Albert \& Charles Boni, 1925.

COLCHIE, Thomas (Ed.). The Penguin Book of Latin American Short Stories. New York: Penguin Books, 1993.

COUTINHO, Afrânio. Machado de Assis na literatura brasileira. In: ASSIS, Machado de. Obra Completa. Vol. 1. Rio de Janeiro: Nova Aguilar, 2004.

DALEY, James (Org.). The World's Greatest Short Stories. New York: Dover Publications, 2006.

GOLDBERG, Isaac (Ed. e trad.). Brazilian Tales. Boston: International Pocket Library, 1965.

HALAMIAN, Leo; KARL, Frederick Robert (Org.). Short Fiction of the Masters. New York: Putnam, 1963.

HOWES, Barbara. The Eyeof The Heart: short stories from Latin America. New York: Avon Books, 1974.

LEVITIN, Alexis (Ed.). Brazil: A Traveler's Literary Companion. Berkeley (CA): Whereabouts Press, 2009.

McNEES, Pat. Contemporary Latin American Short Stories. New York: Ballantine Books, 1974.

PUCHNER, Martin (Org.). The Norton Anthology of World Literature - Volume 2. New York: Norton and Company, 2013.

READER'S DIGEST ASSOCIATION. Great Short Stories of the World. Pleasantville (NY), 1972.

Recebido em: 05/11/2014 Aceito em: 13/01/2015 